\title{
Photocontrol of Flowering and Extension Growth in the Long-day Plant Pansy
}

\author{
Erik S. Runkle1 and Royal D. Heins \\ Department of Horticulture, Michigan State University, East Lansing, MI 48824-1325
}

ADDITIONAL INDEX wORDs. far-red, night interruption, photoperiod, phytochrome, spectral filters, Viola $\times$ wittrockiana

Abstract. Plastics that selectively reduce the transmission of far-red light (FR, 700 to $800 \mathrm{~nm}$ ) reduce extension growth of many floricultural crops. However, FR-deficient $\left(F_{\mathrm{d}}\right)$ environments delay flowering in some long-day plants (LDPs), including 'Crystal Bowl Yellow' pansy (Viola xwittrockiana Gams). Our objective was to determine if FR light could be added to an otherwise $\mathbf{F R}_{\mathrm{d}}$ environment to facilitate flowering with minimal extension growth. In one experiment, plants were grown under a 16-hour $F R_{d}$ photoperiod, and FR-rich light was added during portions of the day or night. For comparison, plants were also grown with a 9-hour photoperiod [short-day (SD) control] or under a neutral (N) filter with a 16-hour photoperiod (long day control). Flowering was promoted most (i.e., percent of plants that flowered increased and time to flower decreased) when FR-rich light was added during the entire 16-hour photoperiod, during the last $\mathbf{4}$ hours of the photoperiod, or during the first or second $\mathbf{4}$ hours after the end of the photoperiod. In a separate experiment, pansy was grown under an $\mathrm{FR}_{\mathrm{d}}$ or $\mathrm{N}$ filter with a 9-hour photoperiod plus $0,0.5,1,2$, or 4 hours of night interruption (NI) lighting that delivered a red $(\mathrm{R}, 600$ to $700 \mathrm{~nm}$ ) to FR ratio of 0.56 (low), 1.28 (moderate), or 7.29 (high). Under the $\mathbf{N}$ filter, the minimum NI duration that increased percent flowering was 2 hours with a moderate or low R:FR and 4 hours with a high R:FR. Under the $F_{\mathrm{d}}$ filter, 2 or 4 hours of NI lighting with a moderate or low R: FR, respectively, was required to increase percent flowering, but a 4-hour NI with a high R:FR failed to promote flowering. Pansy appears to be day-neutral with respect to flower initiation and a quantitative LDP with respect to flower development. The promotion of reproductive development was related linearly to the promotion of extension growth. Therefore, it appears that in LDPs such as pansy, light duration and quality concomitantly promote extension growth and flowering, and cannot readily be separated with lighting strategies.

Buyers of floricultural crops impose strict morphological specifications, especially plant height, on crops they purchase. Chemicals that inhibit various steps in the gibberellin biosynthetic pathway are often used to limit extension growth of herbaceous plants. However, their use can be expensive, is increasingly restricted, and is perceived by some as environmentally unfriendly. Recently, flexible plastic filters that absorb far-red light (FR, 700 to $800 \mathrm{~nm}$ ) have been developed as an alternative method of controlling plant height (Rajapakse et al., 1999; van Haeringen et al., 1998). Although FR-deficient $\left(\mathrm{FR}_{\mathrm{d}}\right)$ environments effectively retard stem extension in many herbaceous species, they can delay flower initiation or development in some long-day plants (LDPs) (Runkle and Heins, 2001).

Plants have been classified into flowering response groups according to how photoperiod influences flowering (Vince-Prue, 1975). Flowering is promoted when LDPs are exposed to night periods shorter than a genotype-specific critical duration. Under short days (SD), an interruption of the dark period with light [known as night interruption (NI) lighting] promotes flowering in LDPs and suppresses it in SD plants (SDPs). To promote reproductive development, most LDP require a long ( $\geq 2 \mathrm{~h}$ ) duration of NI lighting, which is usually most effective at or near the middle of a long (e.g., 15 h) dark period (Lane et al., 1965; Runkle et al., 1998; Vince-Prue, 1975).

Although plants are often classified by their photoperiodic flowering response (SDP or LDP), the photoregulation of flowering can perhaps be described more accurately by whether flowering

Received for publication 23 Sept. 2002. Accepted for publication 31 Mar. 2003. We gratefully acknowledge funding by Michigan's plant agriculture initiative at Michigan State University (Project GREEEN) and greenhouse growers supportive of Michigan State University floricultural research and the support of the Michigan Agricultural Experiment Station. We also thank Dan Tschirhart, David Joeright, and Ron Wik for their greenhouse assistance, British Visqueen for the far-red filter, and Daphne Vince-Prue for her valuable discussions.

'Corresponding author; e-mail runkleer@msu.edu. is controlled primarily by light or dark processes. Plants in which flowering is controlled primarily by light processes, including most LDPs, are known as light-dominant (Thomas and VincePrue, 1997). Light-dominant plants show a more or less quantitative relationship between the irradiance of the night break and the magnitude of the flowering response, until a saturation light intensity, duration, or both are reached. In addition, flowering in light-dominant LDPs often is most rapid when photoperiods contain FR light (Downs and Thomas, 1982; Lane et al., 1965; Runkle and Heins, 2001). Far-red light promotes flowering in light-dominant plants and also promotes internode elongation. Therefore, in light-dominant LDPs, a relatively low ratio of $\mathrm{R}$ (600 to $700 \mathrm{~nm}$ ): FR simultaneously promotes flowering and stem extension, while a high ratio is inhibitory to both responses.

Red and FR light are absorbed by the phytochrome family of photoreceptors, which in many plants regulate growth and development. For any one phytochrome, in the presence of light there exists a photoequilibrium of two interconvertible forms: the $\mathrm{R}$ and FR absorbing forms, which are known as $\mathrm{P}_{\mathrm{r}}$ and $\mathrm{P}_{\mathrm{fr}}$ respectively. Depending on light quality, a phytochrome photoequilibrium [known as $\mathrm{P}_{\mathrm{fr}} /\left(\mathrm{P}_{\mathrm{r}}+\mathrm{P}_{\mathrm{fr}}\right)$, or $\mathrm{P}_{\mathrm{fr}} / \mathrm{P}$ ] is established, where a high R:FR creates a high $\mathrm{P}_{\mathrm{fr}} / \mathrm{P}$, and vice versa. Models based on the distribution of incident spectral radiation have been developed to estimate the $\mathrm{P}_{\mathrm{fr}} / \mathrm{P}$ (Sager et al., 1988). Although these models are based on cross-section phytochrome A data from oats grown in darkness, these estimates and R:FR ratios are useful in associating phytochrome-mediated responses with light quality (Smith, 1994).

Pansy is one of the five best-selling bedding plants in the United States (Behe et al., 2000). 'Crystal Bowl Yellow' pansy is sensitive to light quality with respect to extension growth and flowering (Runkle and Heins, 2001). The objectives of our experiments were to use 'Crystal Bowl Yellow' pansy as a model to 1 ) describe the photoperiodic flowering response, 2) determine 
Table 1. Dates of propagation and forcing, initial node counts, and environmental conditions for experiments with Viola $\times$ wittrockiana 'Crystal Bowl Yellow'. $\mathrm{N}=$ neutral-density filter; $\mathrm{FR}_{\mathrm{d}}=$ far-red $(700$ to $800 \mathrm{~nm})$ deficient filter.

\begin{tabular}{|c|c|c|c|c|c|c|c|c|}
\hline \multirow[b]{2}{*}{ Expt. } & \multirow[b]{2}{*}{ Rep. } & \multicolumn{2}{|c|}{ Date } & \multirow{2}{*}{$\begin{array}{l}\text { Initial } \\
\text { nodes }^{z}\end{array}$} & \multirow{2}{*}{\multicolumn{2}{|c|}{$\begin{array}{c}\text { Avg air } \\
\text { temp during } \\
\text { forcing }\left({ }^{\circ} \mathrm{C}\right)\end{array}$}} & \multirow{2}{*}{\multicolumn{2}{|c|}{$\begin{array}{c}\text { Avg daily } \\
\text { light integral } \\
\text { during forcing } \\
\left(\mathrm{mol} \cdot \mathrm{m}^{-2} \cdot \mathrm{d}^{-1}\right)\end{array}$}} \\
\hline & & Propagation & Forcing & & & & & \\
\hline \multirow[t]{2}{*}{$\overline{\mathrm{I}}$} & 1 & 19 Sept. 1995 & 31 Oct. 1995 & --- & \multicolumn{2}{|c|}{$20.8 \pm 0.3$} & \multicolumn{2}{|c|}{---} \\
\hline & 2 & 16 Jan. 1996 & 29 Feb. 1996 & --- & \multicolumn{2}{|c|}{$21.0 \pm 0.5$} & \multicolumn{2}{|c|}{---} \\
\hline \multirow[t]{4}{*}{ II } & 1 & 14 Sept. 1999 & 9 Oct. 1999 & 2.0 & \multicolumn{2}{|c|}{$20.8 \pm 0.6$} & \multicolumn{2}{|c|}{5.5} \\
\hline & 2 & 1 Nov. 1999 & 24 Nov. 1999 & 2.0 & \multicolumn{2}{|c|}{$20.8 \pm 0.4$} & \multicolumn{2}{|c|}{7.6} \\
\hline & 3 & 13 Dec. 1999 & 12 Jan. 2000 & 2.0 & \multicolumn{2}{|c|}{$20.6 \pm 0.9$} & \multicolumn{2}{|c|}{9.4} \\
\hline & & & & & \multicolumn{4}{|c|}{ Filter treatment } \\
\hline \multirow[t]{3}{*}{ III } & & & & & $\mathrm{N}$ & $\mathrm{FR}_{\mathrm{d}}$ & $\mathrm{N}$ & $\mathrm{FR}_{\mathrm{d}}$ \\
\hline & 1 & 13 Dec. 2000 & 18 Jan. 2000 & 3.0 & $20.3 \pm 0.5$ & $20.5 \pm 0.5$ & 5.8 & 5.5 \\
\hline & 2 & 6 Mar. 2000 & 31 Mar. 2000 & 2.0 & $21.6 \pm 0.8$ & $21.7 \pm 0.4$ & 6.2 & 5.8 \\
\hline
\end{tabular}

zNot recorded.

whether light rich in FR could be added during the day or night in an $\mathrm{FR}_{\mathrm{d}}$ light environment to promote flowering with minimal extension growth, and 3) determine the minimum amount and duration of FR light delivered as an NI for rapid flowering under a neutral or $\mathrm{FR}_{d}$ filter.

\section{Materials and Methods}

Plant material and Culture. Seed of pansy (Viola $\times$ wittrockiana 'Crystal Bowl Yellow') were sown into 288-cell plug trays (6-mL volume) by a wholesale plug producer (Rakers Acres, Litchfield, Mich.), germinated for $\approx 4 \mathrm{~d}$ in darkness, then grown under photoperiods $\geq 14 \mathrm{~h}$ at 20 to $24^{\circ} \mathrm{C}$. Plants were thinned to one per plug. Propagation and forcing dates and node counts at the beginning of experimental treatments are provided in Table 1. Plants were transplanted into $10-\mathrm{cm}(470-\mathrm{mL})$ round pots in Expts. 1 and 2 and into $11-\mathrm{cm}(600-\mathrm{mL})$ round pots in Expt. 3. Media, irrigation, and nutrition were described previously [Runkle et al., 1998 (Expt. 1); Runkle and Heins, 2001 (Expts. 2 and 3)].

GENERAL GREENHOUSE CONDITIONS. All plants were grown in glass greenhouses at $20{ }^{\circ} \mathrm{C}$. Air temperatures were controlled and monitored as reported previously (Runkle and Heins, 2001) and are provided in Table 1 . In all greenhouse areas, from 0600 to $2200 \mathrm{HR}$, high-pressure sodium (HPS) lamps provided a supplemental photosynthetic photon flux $(P P F)$ of 40 to 50 $\mu \mathrm{mol} \cdot \mathrm{m}^{-2} \cdot \mathrm{s}^{-1}$ at canopy level when the ambient greenhouse $P P F$ was $<200 \mu \mathrm{mol} \cdot \mathrm{m}^{-2} \cdot \mathrm{s}^{-1}$ and were shut off when the ambient $P P F$ was $>400 \mu \mathrm{mol} \cdot \mathrm{m}^{-2} \cdot \mathrm{s}^{-1}$. The HPS lamps were positioned above the spectral filters. In all experiments, the 9-h photoperiods were created by opening and closing black cloth at 0800 and $1700 \mathrm{HR}$, respectively. Average photosynthetic daily light integral (DLI; $\left.\mathrm{mol} \cdot \mathrm{m}^{-2} \cdot \mathrm{d}^{-1}\right)$ was measured at canopy level with quantum sensors (LI-189; LI-COR, Lincoln, Nebr.) connected to a datalogger (CR10; Campbell Scientific, Logan, Utah) (Table 1).

Spectral filters. Spectral filters were used in Expts. 2 and 3 to provide two light quality environments [neutral $(\mathrm{N})$ or $\mathrm{FR}_{\mathrm{d}}$ ] with similar daily light integrals. The $\mathrm{N}$ filter was a metalized woven shading fabric [PLS Clear (Ludvig Svensson, Charlotte, N.C.)] and the $\mathrm{FR}_{\mathrm{d}}$ filter was a plastic that selectively reduced the transmission of FR light (van Haeringen et al., 1998). Both filters reduced photosynthetic active radiation $(P A R)$ by $\approx 25 \%$. Solar spectra transmissions through the filters were as reported previously (Runkle and Heins, 2001). Treatments using neither the $\mathrm{N}$ or $\mathrm{FR}_{\mathrm{d}}$ filter are described as unfiltered in this report.

Photoperiod (Expt. 1). To determine the photoperiodic flowering response of 'Crystal Bowl Yellow', eight or 10 plants were grown under each of seven photoperiod treatments: 10, 12, $13,14,16$, or $24 \mathrm{~h}$ of light or $9 \mathrm{~h}$ photoperiod with a 4-h $(2200$ to $0200 \mathrm{HR}$ ) NI. Photoperiods $>9 \mathrm{~h}$ were achieved with 9 -h photoperiods extended by supplemental lighting from $1700 \mathrm{HR}$ until each photoperiod was completed. Photoperiod-extension and NI lighting were delivered by incandescent (INC) lamps under the black cloth providing 1 to $3 \mu \mathrm{mol} \cdot \mathrm{m}^{-2} \cdot \mathrm{s}^{-1}$ at canopy level. The experiment was performed twice.

Timing OF FR LIGHT DELIVERY (ExPT. 2). To determine whether light rich in FR could be added to an otherwise FR $_{\mathrm{d}}$ long day (LD) to facilitate rapid flowering with minimal internode extension, plants were exposed to one of nine filter and lighting treatments: an unfiltered 9-h photoperiod, a 16-h photoperiod under the $\mathrm{N}$ filter, a 16-h photoperiod under the $\mathrm{FR}_{\mathrm{d}}$ filter, or a 16-h photoperiod under the $\mathrm{FR}_{\mathrm{d}}$ filter with lighting from INC lamps (delivering .2.3 and $4.0 \mu \mathrm{mol} \cdot \mathrm{m}^{-2 \cdot} \cdot \mathrm{s}^{-1}$ of R and FR light, respectively) positioned

Table 2. Spectral radiation and estimated phytochrome photoequilibria $\left(\mathrm{P}_{\mathrm{fr}} / \mathrm{P}\right.$; Sager et al., 1988) under neutral $(\mathrm{N})$ or far-red deficient $\left(\mathrm{FR} \mathrm{f}_{\mathrm{d}}\right)$ filters, and under lamps used for night interruption lighting: incandescent (INC), soft-white fluorescent (SWF), or both. All lamps were surrounded with a filter to reduce the transmission of blue (B) light (400 to $500 \mathrm{~nm})$. An N filter surrounded the combined INC $+\mathrm{SWF}$ lamps to provide a more similar photosynthetic photon flux $(P P F)$ among light quality treatments. $\mathrm{R}=$ red light (600 to $700 \mathrm{~nm}) ; \mathrm{FR}=$ far-red light $(700$ to $800 \mathrm{~nm})$.

\begin{tabular}{|c|c|c|c|c|c|}
\hline \multirow[b]{2}{*}{ Parameter } & \multicolumn{2}{|c|}{ Filter } & \multicolumn{3}{|c|}{$\operatorname{Lamp}(\mathrm{s})$} \\
\hline & $\mathrm{N}$ & $\mathrm{FR}_{\mathrm{d}}$ & INC & $\mathrm{INC}+\mathrm{SWF}$ & SWF \\
\hline$\% \mathrm{~B}^{\mathrm{z}}$ & 18 & 20 & 1 & 2 & 4 \\
\hline$\% \mathrm{R}$ & 29 & 28 & 31 & 41 & 51 \\
\hline$\% \mathrm{FR}$ & 27 & 19 & 55 & 32 & 7 \\
\hline $\mathrm{P}_{\mathrm{fr}} / \mathrm{P}$ & 0.72 & 0.77 & 0.64 & 0.74 & 0.8 \\
\hline$\sum(400$ to $800 \mathrm{~nm}) \mathrm{y}$ & & & 13.1 & 10.2 & 9.6 \\
\hline
\end{tabular}

zPercentage of light from 400 to $800 \mathrm{~nm}$ within indicated waveband. y $\mu \mathrm{mol} \cdot \mathrm{m}^{-2} \cdot \mathrm{s}^{-1}$. 


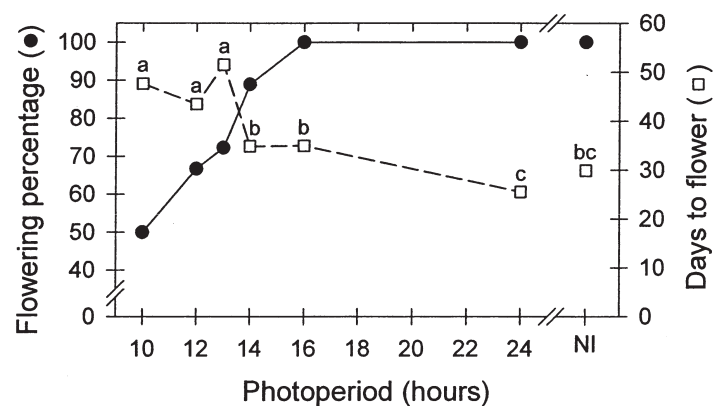

Fig. 1.Percent of Viola $\times$ wittrockiana 'Crystal Bowl Yellow' plants flowering, and days to flower, under photoperiods consisting of 9-h natural days extended with light from incandescent lamps. $\mathrm{NI}=9$-h photoperiods plus 4-h night interruption Plants were considered nonflowering if they did not reach anthesis within 98 to $100 \mathrm{~d}$ from seed. Days to flower with the same letter are not statistically different at $P=0.05$

below filters from 0600 to $2200 \mathrm{HR}, 0600$ to $1000 \mathrm{HR}, 1200$ to $1600 \mathrm{HR}, 1800$ to $2200 \mathrm{HR}, 2200$ to $0200 \mathrm{HR}$, or 0200 to $0600 \mathrm{HR}$. The experiment was performed three times, with 20 plants per treatment and replication.

Night INTERRUPTION LIGHTING (ExPT. 3). An alternative lighting strategy was developed to determine whether NI lighting could be used in an $\mathrm{FR}_{\mathrm{d}}$ environment to promote rapid flowering with minimal stem extension. Twenty-six wooden chambers $(55 \mathrm{~cm}$ $\times 75 \mathrm{~cm} \times 64 \mathrm{~cm}$ ) were constructed with open tops and open southward-facing sides. The chambers were placed on the greenhouse benches, and half of the chambers were covered with the $\mathrm{N}$ filter and half with the $\mathrm{FR}_{\mathrm{d}}$ filter. To minimize any temperature increase, chambers were continually ventilated with exhaust fans (model 4C548; Dayton Electric, Chicago) that provided $\approx 5.8$ air exchanges/min. The outlet air temperature of each chamber was recorded (Table 1).

Plants were grown under a 9-h photoperiod. Inside each chamber, one of three light sources provided NI lighting that delivered an R:FR of 0.56 (low), 1.28 (moderate), or 7.29 (high). The low, high, or moderate R:FR was provided by an INC lamp, a soft-white fluorescent (SWF) lamp, or an INC and an SWF lamp, respectively. Electrical timers were used to turn lamps on midway through the 15 -h dark periods (at $0030 \mathrm{HR}$ ) for $0,0.5,1$, 2 , or $4 \mathrm{~h}$. All lamps were surrounded with a filter (Lee filter 101, Andover, United Kingdom) to reduce the transmission of blue (400 to $500 \mathrm{~nm}$ ) light. In addition, an N filter (OLS50; Ludvig Svensson) surrounded the combined lamps to provide a more similar $P P F$ among light quality treatments (Table 2).

Data COllection and analysis. Experiments were replicated in time and treatments were arranged in a completely randomized design. Plants were considered nonflowering if they did not bloom within 56, 95, or $65 \mathrm{~d}$ of forcing in Expts. 1, 2 or 3, respectively. The date the first flower bud was visible (without dissection) and the date the first flower reached anthesis on the apical stem (apical flowering; typical) or a lateral stem (lateral flowering; atypical) were recorded for each plant. At flowering, visible flower buds above the first open flower and nodes on the main stem below the first open flower were counted. In Expts. 2 and 3, total plant height (from soil level) was measured. Node count increase to the first open flower, days to visible bud (VB), days from VB to flower, and days to flower from the start of forcing were calculated. Internode length was calculated for flowering plants by dividing main stem length by the node count and, for nonflowering plants, determining the average internode length of the first 10 nodes from the start of forcing. Data were analyzed by using analysis of variance (ANOVA), general linear models (GLM) procedures, and a mean separation procedure for unequal observation numbers (pdiff) with $P=0.05$ (SAS Institute, Cary, N.C.). Regression analysis was performed by Sigma Plot (SPSS, Inc., Chicago).

\section{Results}

Photoperiod (Expt. 1). Percent of 'Crystal Bowl Yellow' plants that flowered increased from 50 to 100 as the photoperiod increased from 10 to $16 \mathrm{~h}$ (Fig. 1). Time to flower decreased as the photoperiod increased and was most rapid under continual (24 h) light or a 4-h NI. Flowering plants developed $\geq 10$ nodes before flowering under photoperiods $\leq 13 \mathrm{~h}$, and $\leq 8.4$ nodes under longer photoperiods or NI (data not shown).

Timing OF FR Light DeLIVERY (ExPT. 2). Percent of plants that flowered on an apical stem was 52 or 98 under unfiltered 9-h or $\mathrm{N}$ filtered 16 -h photoperiods, respectively, but was reduced to $28 \%$ when 16-h photoperiods were deficient in FR (Fig. 2A and B). Half of the plants flowered on an apical stem when INC light was added to the 16-h $\mathrm{FR}_{\mathrm{d}}$ photoperiod in the morning (0600 to 1000 HR) or midday (1200 to $1600 \mathrm{HR}$ ). Apical flowering was increased further $(\geq 72 \%)$ when INC light was added before or after the end of the 16-h $\mathrm{FR}_{\mathrm{d}}$ photoperiod, but was not as high as that under $\mathrm{N}$ filtered 16 -h photoperiods. Lateral flowering percentage generally was highest under conditions that inhibited apical flowering.

Flowering was most rapid under $\mathrm{N}$ filtered 16 -h photoperiods or when INC lighting was added to $\mathrm{FR}_{\mathrm{d}}$ photoperiods after 1800 HR and before $1000 \mathrm{HR}$ (Fig. 2C and D). Regardless of photoperiod or lighting treatment, plants initiated flowers at the same node (Fig. 2E and F). Conditions that were least favorable for flowering (e.g., 9-h unfiltered or 16-h FR $\mathrm{f}_{\mathrm{d}}$ photoperiod) caused development of more nodes before anthesis compared with the most inductive treatments. Peduncles of flowering plants were longest under conditions that were most favorable for flowering: $\mathrm{N}$ filtered 16-h photoperiods or when INC light was delivered before or after the end of the 16-h FR $\mathrm{d}_{\mathrm{d}}$ photoperiod (Fig. 2G and $\mathrm{H})$. Except when grown under 9-h days or a $16-\mathrm{h} \mathrm{FR}_{\mathrm{d}}$ environment with INC lighting from 0600 to $1000 \mathrm{HR}$, total height of flowering plants was similar (data not shown).

Night INTERRUPTION Lighting (ExPT. 3). Regardless of NI lighting, percentage of plants flowering on an apical stem (Fig. $3 \mathrm{~A}$ and $\mathrm{B}$ ) and stem length (Fig. 3E and $\mathrm{F}$ ) of pansy were reduced (by $20 \%$ and $28 \%$, respectively) when the 9 -h photoperiod was deficient in FR. Of the plants that flowered under the FR $\mathrm{d}_{\mathrm{d}}$ base photoperiod (in boxes covered with the $\mathrm{FR}_{\mathrm{d}}$ filter), average time to anthesis was increased (by $4 \mathrm{~d}$ ) compared with that of flowering plants under the $\mathrm{N}$ filter (Fig. 3C and D). In general, flowering percentage increased as the NI duration increased, but the response varied by the quality of NI light provided (Fig. 3A and B). Under the $\mathrm{N}$ filter, compared to plants without NI lighting, the minimum NI duration that increased flowering percentage was $2 \mathrm{~h}$ when the NI R:FR was low or moderate and $4 \mathrm{~h}$ when the ratio was high (Fig. 3A). Under the $\mathrm{FR}_{\mathrm{d}}$ filter, NI durations of $2 \mathrm{~h}$ were required with moderate R:FR or $4 \mathrm{~h}$ with low R:FR to increase flowering percentage compared with that of plants without an NI (Fig. 3B). A 4-h NI with a high R:FR failed to promote flowering under an $\mathrm{FR}_{\mathrm{d}}$ environment. Axillary flowering percentage was highest under the high R:FR (13\%) compared with a low (7\%) or moderate $(6 \%) \mathrm{R}: \mathrm{FR}$ and lowest when the NI was $4 \mathrm{~h}$ (2.5\% compared with $\geq 7.5 \%$ under shorter NI durations; data not shown).

Time to anthesis decreased as the NI duration increased, but 

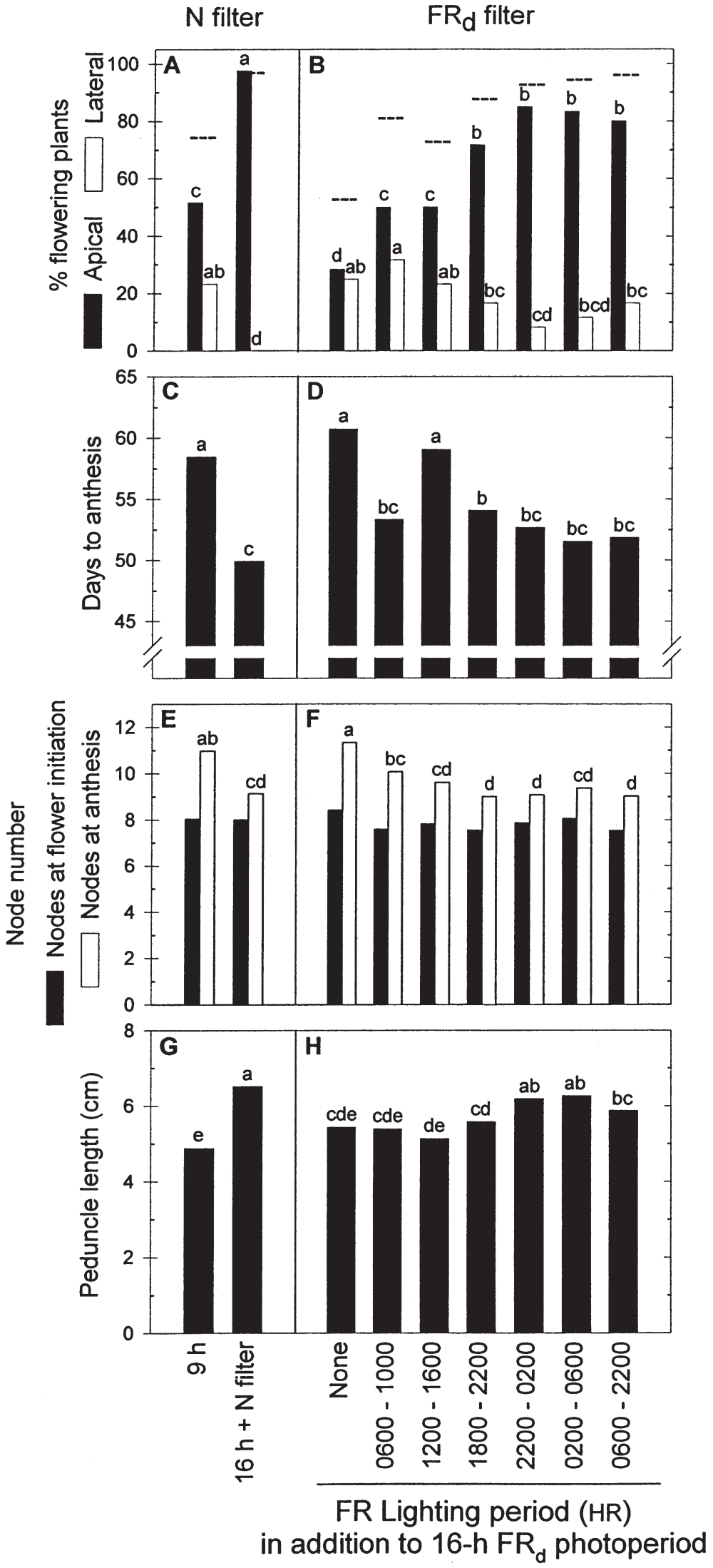

Fig. 2. Percent of plants that flowered, days to anthesis, node counts and peduncle length of Viola $\times$ wittrockiana 'Crystal Bowl Yellow' grown under a neutral (N) filter (A, C, E, and G) or a filter that selectively reduced the transmission of far-red (FR, 700 to $800 \mathrm{~nm})$ light $\left(\mathrm{FR}_{\mathrm{d}}\right.$ filter $)$ $(\mathbf{B}, \mathbf{D}, \mathbf{F}$, and $\mathbf{H})$. Incandescent lamps were used to provide light rich in FR under the FR filter for periods during the day or night, as indicated. Except for the 9-h photoperiod, a 16-h base photoperiod was provided by natural photoperiods extended with light from high-pressure sodium lamps from 0600 to $2200 \mathrm{HR}$, positioned above filters. In Figs. A and B, - - represents the total percentage of plants that flowered. Apical flowering is typical. Values with the same letter within measurement are not statistically different at $P=0.05$. Letters are not provided when all treatments are statistically similar.

the magnitude varied with the R:FR (Fig. 3C and D). One hour of NI lighting significantly accelerated flowering under the $\mathrm{N}$ filter when delivered with a low or moderate $\mathrm{R}: \mathrm{FR}$, but $4 \mathrm{~h}$ of lighting with a high R:FR was required to hasten flowering. A 4-h NI with a low or moderate R: FR hastened flowering by $18 \mathrm{~d}$ under the $\mathrm{N}$ filter and 14 $\mathrm{d}$ under the FR $\mathrm{F}_{\mathrm{d}}$ filter. Plants provided with a 4-h NI with a high R:FR flowered 7 or 8 d earlier than plants without an NI, regardless of filter type.

An NI of $\leq 1 \mathrm{~h}$ had little or no effect on stem extension, regardless of NI light quality (Fig. 3E and F). However, compared with that of plants without an NI, stem length increased by $\geq 138 \%$ or $\geq 103 \%$ when a 4 -h NI was delivered with low or moderate R:FR, respectively, regardless of light quality during the base photoperiod. In contrast, a 4-h NI with a high R:FR promoted stem extension by $\leq 35 \%$.

Light quality during the base photoperiod did not have a significant effect on the node at flower initiation or anthesis (Table 3), so data within filter treatments were pooled. Pansy initiated flowers at the same node, regardless of NI duration or quality (Fig. 4A). However, compared to plants without an NI, fewer nodes developed before anthesis when the NI was $\geq 2 \mathrm{~h}$ with a low R:FR or $4 \mathrm{~h}$ with a moderate R:FR (Fig. 4B). An NI with a high R: FR did not reduce the number of nodes developed before anthesis compared with that of plants under SDs.

\section{Discussion}

Half of the 'Crystal Bowl Yellow' pansy plants under unfiltered 9- or 10-h photoperiods reached anthesis within the experimental periods. Flowering percentage increased and time to flower decreased as the photoperiod increased, until $16 \mathrm{~h}$, when essentially all plants flowered under unfiltered photoperiods extended with INC or HPS lamps. Continual photoperiods $\geq 16 \mathrm{~h}$ and a $4-\mathrm{h}$ NI with INC lamps promoted flowering similarly. Therefore, 'Crystal Bowl Yellow' is a quantitative LDP, as is 'Universal Violet' pansy (Adams et al., 1997).

In all experiments, 'Crystal Bowl Yellow' initiated flowers at about the eighth node, regardless of the duration or spectral quality of the photoperiod. However, flower bud development was arrested when photoperiods were short or when long photoperiods were deficient in FR light. When 16-h photoperiods were deficient in FR, flowering was suppressed more than that under unfiltered 9-h photoperiods. Therefore, we can further characterize the photoperiodic response of pansy as a day-neutral plant with respect to flower initiation, and a quantitative LDP with respect to flower development. In addition, pansy can be considered a 

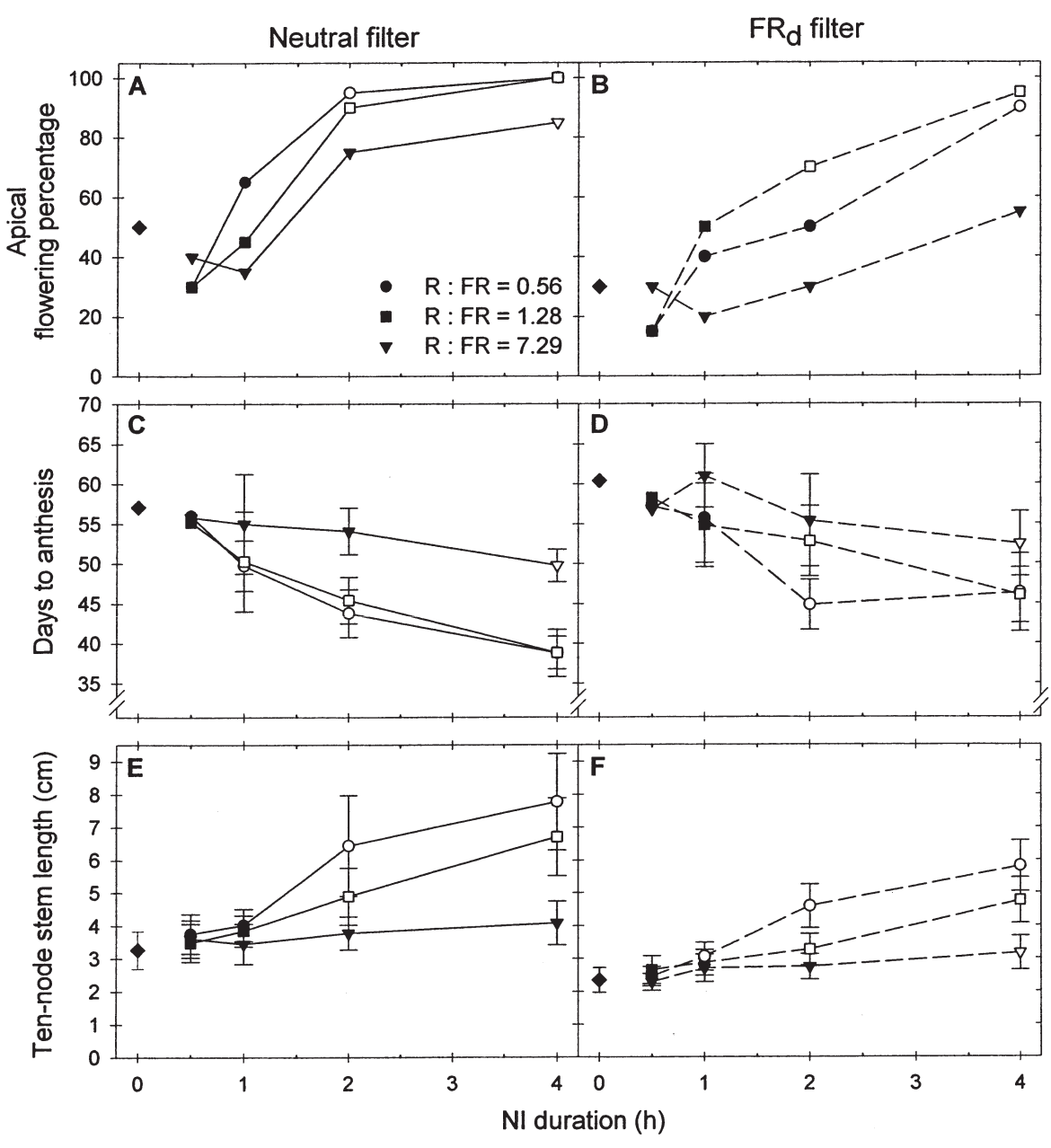

Experiments 2 and 3 were performed to determine whether pansy could be exposed to a minimal amount of FR light to promote flower development without promoting stem extension. Light from INC lamps, which is rich in FR, added during the first $10 \mathrm{~h}$ of the base photoperiod had little or no promotive effect on flowering or stem extension. Flowering was promoted when light from INC lamps was added at the end of or continually during the base photoperiod, or during the otherwise dark period. Plants lighted from 2200 to $0200 \mathrm{HR}$ or from 0200 to $0600 \mathrm{HR}$ received a 20 -h photoperiod, and thus at least some of the promotion of flowering could be attributed to the increase in light duration. However, regardless of the addition of FR light, the percentage of plants with a normal flowering phenotype (apical flowering) was always lower under the $\mathrm{FR}_{\mathrm{d}}$ filter compared with that under the $\mathrm{N}$ filter. Furthermore, the addition of FR promoted both flowering and extension growth. Therefore, exposing plants to an FR-rich environment for portions of the day or night is not an effective strategy for promoting flowering without promoting extension growth.

The maximum predicted $\mathrm{P}_{\mathrm{fr}} / \mathrm{P}$ in an environment completely devoid of FR light is $\approx 0.89$, since there is considerable overlap in the $\mathrm{R}$ - and FR-absorbing forms of phytochrome in the 650 to $700 \mathrm{~nm}$ waveband (Sager et al., 1988). The estimated $\mathrm{P}_{\mathrm{fr}} / \mathrm{P}$ under the $\mathrm{FR}_{\mathrm{d}}$ filter was $\approx 0.78$ to 0.80 , which is significantly greater

Fig. 3. Percentage of plants that flowered on the apical stem, days to flower, and stem length of Viola $\times$ wittrockiana 'Crystal Bowl Yellow' grown under a 9-h photoperiod under a neutral filter $(\mathbf{A}, \mathbf{C}$, and $\mathbf{E})$ or a filter that selectively reduced the transmission of far-red (FR, 700 to $800 \mathrm{~nm}$ ) light $(\mathbf{B}, \mathbf{D}$, and F). Night interruption (NI) lighting was provided for various durations by lamps delivering a low $(\mathbf{0}, 0.56)$, moderate $(\boldsymbol{\square}, 1.28)$, or high $(\boldsymbol{\nabla}, 7.29)$ red $(\mathrm{R}, 600$ to $700 \mathrm{~nm}$ ) to FR ratio (Table 2). In each graph, open or dark symbols represen means significantly different (at $P=0.05$ ) from or similar to treatments withou an NI $($ ), respectively. Error bars represent $95 \%$ confidence intervals, and except for $\mathbf{A}$ and $\mathbf{B}$, are not presented for statistically similar NI lighting treatments.

light-dominant plant since 1) it required a long period (e.g., $\geq 2$ h) of night break lighting to maximally promote flowering and 2) the promotion of flowering depended on the spectral quality of incident radiation, with a low or moderate R:FR more effective

than a high R:FR. than that of unfiltered sunlight $\left(\mathrm{P}_{\mathrm{fr}} / \mathrm{P} \approx 0.71\right.$ to 0.72$)$. Although the $\mathrm{FR}_{\mathrm{d}}$ filter reduced the transmission of FR radiation, particularly around $730 \mathrm{~nm}$, a substantial amount of FR radiation penetrated the filter when the ambient light intensity was high. However, stem extension and flowering were suppressed when the $\mathrm{P}_{\mathrm{f}} / \mathrm{P}$ was increased, even though plants were exposed to some FR light.

Our studies indicate that a moderately low $\mathrm{P}_{\mathrm{fr}} / \mathrm{P}($ e.g., $<0.78)$ is required toward the end of the photoperiod for normal flower development in pansy (Expt. 2). A requirement for a high $\mathrm{P}_{\mathrm{fr}} / \mathrm{P}$, especially toward the end of the photoperiod, has been reported for rapid initiation in otherLDP(Carr-Smith et al., 1989). For example, in the LDP Lolium temulentum L., FR promoted flowering during the first $\approx 6 \mathrm{~h}$ of a 16 - $\mathrm{h}$ night, and $\mathrm{R}$ was most promotive toward the end of the night (Evans, 1976; Vince, 1965). Although most

Table 3. Analysis of variance (ANOVA) for various flowering and extension growth parameters of Viola xwittrockiana 'Crystal Bowl Yellow' as influenced by filter treatment during the photoperiod and the quality and duration of night interruption (NI).

\begin{tabular}{|c|c|c|c|c|c|c|c|}
\hline $\begin{array}{l}\text { Source of } \\
\text { variation }\end{array}$ & df & $\begin{array}{c}\text { Apical } \\
\text { flowering } \\
\text { percentage }\end{array}$ & $\begin{array}{c}\text { Node at } \\
\text { flower } \\
\text { initiation }\end{array}$ & $\begin{array}{l}\text { Node at } \\
\text { anthesis }\end{array}$ & $\begin{array}{l}\text { Days to } \\
\text { anthesis }\end{array}$ & Peduncle & $\begin{array}{l}\text { Stem } \\
\text { length }\end{array}$ \\
\hline$\overline{\text { Filter }(\mathrm{F})}$ & 1 & $* * *$ & NS & NS & $* * *$ & $* * *$ & $* * *$ \\
\hline NI quality (Q) & 2 & $* *$ & NS & $* * *$ & $* * *$ & $* * *$ & $* * *$ \\
\hline NI duration (D) & 3 & $* * *$ & NS & $* * *$ & $* * *$ & $* * *$ & $* * *$ \\
\hline $\mathrm{F} \times \mathrm{Q}$ & 2 & NS & NS & NS & NS & NS & NS \\
\hline $\mathrm{F} \times \mathrm{D}$ & 3 & NS & NS & NS & NS & NS & NS \\
\hline $\mathrm{Q} \times \mathrm{D}$ & 6 & $*$ & NS & NS & $* *$ & NS & $* * *$ \\
\hline $\mathrm{F} \times \mathrm{Q} \times \mathrm{D}$ & 6 & NS & NS & NS & NS & NS & NS \\
\hline
\end{tabular}

Ns,*,**,***Nonsignificant or significant at $P<0.05,0.01$, or 0.001 , respectively. 


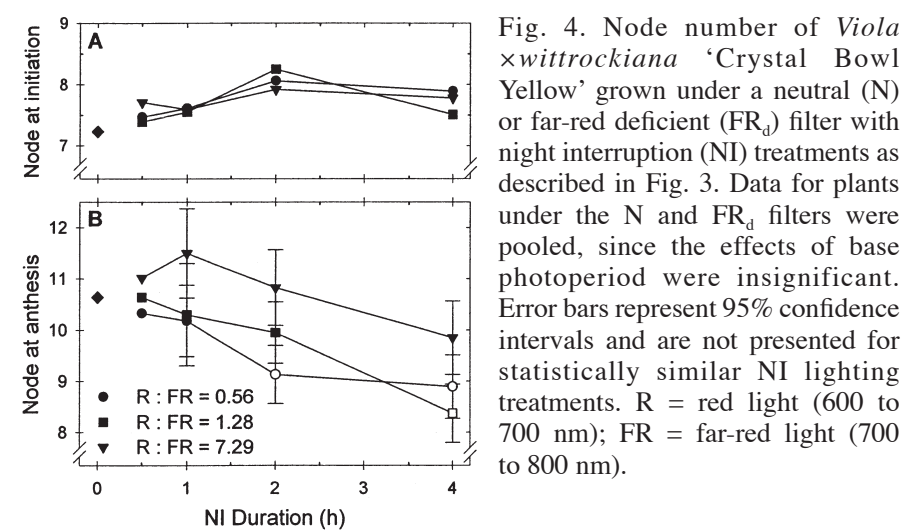

studies have described an FR requirement for flower initiation, our results with pansy are similar to those with Hyoscyamus niger L., where the primary effect of FR light is on flower development, not initiation (Downs and Thomas, 1982).

A high $\mathrm{P}_{\mathrm{fr}} / \mathrm{P}$ during the base photoperiod inhibited flowering, regardless of NI lighting duration or spectral quality (Expt. 3), which suggests that, in addition to the end-of-day FR requirement, a moderate or low $\mathrm{P}_{\mathrm{fr}} / \mathrm{P}(<0.80)$ is required during the base photoperiod for rapid and complete flowering of pansy. This supposition is supported by Expt. 2, in which flowering percentage under the $\mathrm{FR}_{\mathrm{d}}$ filter was never as high as that under the $\mathrm{N}$ filter, regardless of lighting treatment.

Flowering is promoted most in light-dominant LDP when an $\mathrm{NI}$ is long (e.g., $\geq 2 \mathrm{~h}$ ) and contains FR light (Lane et al., 1965). In pansy, flowering was promoted most when the night break was for $4 \mathrm{~h}$ and the R:FR was relatively low (e.g., $\leq 1.28)$. An NI $\leq 1 \mathrm{~h}$ had no promotive effect on percent of plants that flowered, regardless of the light quality provided during the day or night. Except for $1 \mathrm{~h}$ of NI with INC lamps, an NI $\leq 1 \mathrm{~h}$ did not significantly promote stem extension in any treatment. The conditions that most promoted flowering (e.g., a 4-h NI with a low or moderate $\mathrm{R}: \mathrm{FR})$ were also most promotive to extension growth. Together, the results suggest that flower development and stem extension are promoted similarly by the quality and duration of NI.

To quantify the relationship between stem extension (SE) and flowering promotion (FP), indices were developed for each of the 26 treatments used in Expt. 3. The FP index (adapted from Lange, 1993) and SE index of each treatment were determined by:

$\mathrm{SE}=\mathrm{I}_{\mathrm{t}} \times \mathrm{I}_{\max }^{-1}$

$\mathrm{FP}=\mathrm{F} \times \mathrm{FT}_{\text {min }} \times \mathrm{FT}_{\mathrm{t}}^{-1}$

where $I_{t}=$ treatment average internode length $(\mathrm{mm}), \mathrm{I}_{\max }=$ maximum average internode length $(\mathrm{mm}), \mathrm{F}=$ flowering $(\%), \mathrm{FT}_{\min }=$ minimum average flowering time $(\mathrm{d})$, and $\mathrm{FT}_{\mathrm{t}}=$ treatment average flowering time (d). In our studies, plants under the $\mathrm{N}$ filter with a 4-h NI from INC lamps flowered most rapidly and had the greatest internode length, and thus were the values used for $\mathrm{I}_{\max }$ and $\mathrm{FT}_{\min }$ (Fig. 3C and E).

Regardless of light quality during the photoperiod or the NI light quality or duration, the promotion of extension growth was related linearly to the promotion of reproductive development (Fig. 5). This observation suggests that in light-dominant LDP such as pansy, light duration and quality concomitantly promote extension growth and flowering, and it does not appear that they can readily be separated with lighting strategies.

A variety of phytochrome-mediated processes, including extension growth and flowering, are mediated by the gibberellin (GA) family of plant hormones. Application of GA hastened flowering in pansy, and increased internode elongation (Misra and Singh,

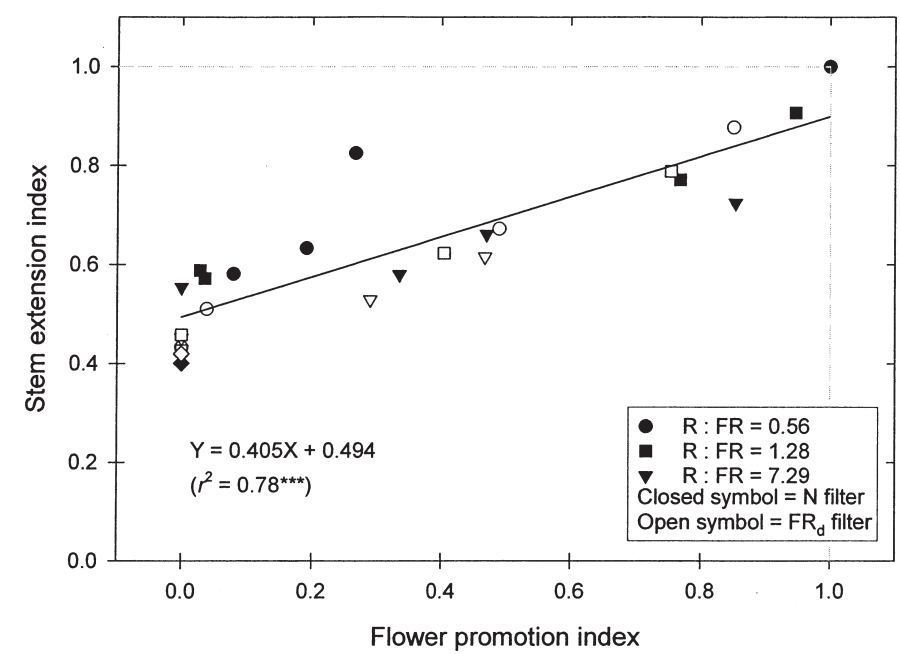

Fig. 5. Stem extension and flower promotion of Viola $\times$ wittrockiana 'Crystal Bowl Yellow' grown under 26 combinations of filter and night interruption treatments, as described in Fig. 3. Linear regression analysis was used to relate the relative promotion of stem extension with flowering; see text for equations. $\mathrm{R}=$ red light $(600$ to $700 \mathrm{~nm}) ; \mathrm{FR}=$ far-red light $(700$ to $800 \mathrm{~nm})$. ${ }^{* * *}$ Significant at $P \leq 0.0001$.

1977). Chemicals that inhibit various steps in the gibberellin biosynthetic pathway limit extension growth of herbaceous plants, but their ability to do so without inhibiting flowering varies among species and chemicals. GA inhibitors delayed flowering in Aster novi-belgii L. (Whipker et al., 1995), Dahlia variabilis Willd., (Whipker and Hammer, 1997), Easter lily (Lilium longiflorum Thunb.) (Heins, 1993; Lewis and Lewis, 1981) and two cultivars of Scaevola (Starman and Williams, 2000). No delay in flowering was observed in poinsettia (Euphorbia pulcherrima Willd. ex Klotzsch) (Faust et al., 2001). Dahlia and Euphorbia are classified as SDP, Lilium is an LDP, and Aster is a long-short day plant (LSDP) (Thomas and Vince-Prue, 1997) while flowering of Scaevola is not influenced by photoperiod (unpublished data).

A close relationship between phytochrome, GAs, flowering, and extension growth has been demonstrated by several studies. In transgenic aspen (Populus tremula $\times$ tremuloides), the overexpression of phytochrome A (phyA) reduced internode length, which was correlated with low levels of GAs in apical stem and leaf tissue (Olsen et al., 1997). Similarly, transgenic tobacco and potato with overexpressed phyA exhibited dwarfism (Heyer et al., 1995; Jordan et al., 1995). Phytochrome A-deficient mutants of Arabidopsis thaliana Heynh. are relatively insensitive to FR and LD, and Reed et al. (1994) have suggested that this phytochrome participates in the regulation of extension growth and flowering. In the LDP Nicotiana sylvestris Speg. \& Comes, phytochrome B overexpression concomitantly reduced internode extension and delayed flowering (J. Metzger, personal communication). Therefore, it appears that regulating the phytochrome status by using lighting or molecular manipulation of constitutive expression are not effective strategies for suppressing extension growth without inhibiting flowering.

In summary, these experiments indicate that, although an $\mathrm{FR}_{\mathrm{d}}$ environment can limit extension growth, it also delays flowering in light-dominant LDP such as pansy under our experimental conditions. Exposure of plants to periods of FR light can partially, but not completely, overcome a delay in flowering. However, when light conditions promote flowering, they also promote extension growth. Therefore, commercial use of an FR filter will be limited when rapid and complete flowering of LDP is desired. 


\section{Literature Cited}

Adams, S.R., S. Pearson, and P. Hadley. 1997. The effects of temperature, photoperiod and light integral on the time to flowering of pansy cv. Universal Violet (Viola ×wittrockiana Gams.). Ann. Bot. 80:107-112.

Behe, B., J. Hardy, J. Heilig, and A. Scordalakes. 2000. 1999 season sales summary. Ohio Florists' Assn. Bul. (March):1-12.

Carr-Smith, H.D., C.B. Johnson, and B. Thomas. 1989. Action spectrum for the effect of day-extensions on flowering and apex elongation in green, light-grown wheat (Triticum aestivum L.). Planta 179: 428-432.

Downs, R.J. and J.F. Thomas. 1982. Phytochrome regulation of flowering in the long-day plant, Hyoscyamus niger. Plant Physiol. 70: 898-900.

Evans, L.T. 1976. Inflorescence initiation in Lolium temulentum L.: XIV. The role of phytochrome in long day induction. Austral. J. Plant Physiol. 3:207-217.

Faust, J.E., P.C. Korczynsiki, and R. Klein. 2001. Effects of paclobutrazol drench application date on poinsettia height and flowering. HortTechnology 11:557-560.

Heins, R.D. 1993. Sumagic's effect on Easter lilies. Greenhouse Grower 11:44-50.

Heyer, A.G., D. Mozley, V. Landschütze, B. Thomas, and C. Gatz. 1995 Function of phytochrome A in potato plants as revealed through the study of transgenic plants. Plant Physiol. 109:53-61.

Jordan, E.T., P.M. Hatfield, D. Hondred, M. Talon, J.A.D. Zeevaart, and R.D. Vierstra. 1995. Phytochrome A overexpression in transgenic tobacco. Plant Physiol. 107:797-805.
Lane, H.C., H.M. Cathey, and L.T. Evans. 1965. The dependence of flowering in several long-day plants on the spectral composition of light extending the photoperiod. Amer. J. Bot. 52:1006-1014.

Lange, N. 1993. Modeling flower induction in Lolium longiflorum. MS thesis. Mich. State Univ., East Lansing.

Lewis, A.H. and J.S. Lewis. 1981. Improving ancymidol efficiency for height control of Easter lily. HortScience 16:89-90.

Misra, L.P. and M.M. Singh. 1977. Effect of growth regulators on growth and flowering of pansy (Viola tricolor). Progressive Hort. 9:61-64.

Olsen, J.E., O. Junttila, J. Nilsen, M.E. Eriksson, I. Martinussen, O. Olsson, G. Sandberg, and T. Moritz. 1997. Ectopic expression of oat phytochrome A in hybrid aspen changes critical daylength for growth and prevents cold acclimatization. Plant J. 12:1339-1350.

Rajapakse, N.C., R.E. Young, M.J. McMahon, and R. Oi. 1999. Plant height control by photoselective filters: Current status and future prospects. HortTechnology 9:618-624.

Reed, J.W., A. Nagatani, T.D. Elich, M. Fagan, and J. Chory. 1994. Phytochrome A and phytochrome B have overlapping but distinct functions in Arabidopsis development. Plant Physiol. 104:1139-1149.

Runkle, E.S. and R.D. Heins. 2001. Specific functions of red, far red, and blue light in flowering and stem extension of long-day plants. J. Amer. Soc. Hort. Sci. 126:275-282.

Runkle, E.S., R.D. Heins, A.C. Cameron, and W.H. Carlson. 1998. Flowering of herbaceous perennials under various night interruption and cyclic lighting treatments. HortScience 33:672-677.

Sager, J.C., W.O. Smith, J.L. Edwards, and K.L. Cyr. 1988. Use of spectral data to determine photosynthetic efficiency and phytochrome photoequilibria. Trans. ASAE 31:1882-1889. 